\title{
Urea Concentration Profiles from Kokum Wax Coated Briquettes
}

\author{
M.Ramananda Bhat ${ }^{1, *}$, D.V.R.Murthy ${ }^{2}$, M.B.Saidutta ${ }^{2}$, Sahitya Reddivari ${ }^{3}$ \\ ${ }^{1}$ Department of Biotechnology, Manipal Institute of Technology, Manipal University, India \\ ${ }^{2}$ Department of Chemical Engineering, National Institute of Technology Surathkal, Mangalore, India \\ ${ }^{3}$ Undergraduate student, Department of Biotechnology, Manipal Institute of Technology, Manipal, India \\ *Corresponding Author: bhatchem@gmail.com
}

Copyright (C 2014 Horizon Research Publishing All rights reserved.

\begin{abstract}
Urea briquettes suffer from major disadvantages such as relatively rapid dissolution, high soil urea concentration around shrinking briquette and susceptibility to leaching losses. Coatings, such as kokum wax applied on the briquettes, can mitigate these problems. Concentrations of urea developed in soil, due to release from kokum wax coated briquettes, were experimentally measured in silt loam soil. High soil urea concentrations as observed in the case of uncoated briquettes were not observed, thereby alleviating the ill effects of high concentration of soil urea.
\end{abstract}

Keywords Briquette, Kokum, Wax, Urea, Release, Coating

\section{Introduction}

Urea briquettes are used in many of the Asian countries in order to combat some of the disadvantages of surface applied prilled urea, such as leaching losses and surface run off in agricultural fields [1]. But the briquettes themselves per se are not of slow release in nature and suffer from some disadvantages such as fast dissolution and high concentration of urea around the shrinking briquettes [2]. This high soil urea concentration can lead to burnout of plant roots and adversely affect plant growth. Hence, it becomes necessary to retard the dissolution by applying a coating around the briquettes. Kokum wax and paraffin wax are two such materials studied from the perspective of urea release [3].

Although both the coatings succumbed to rupture and subsequent release form the ruptured locations, it becomes essential to experimentally measure the concentration of urea around the shrinking briquette and compare it with the corresponding urea concentrations from uncoated shrinking briquettes in soil. Thus, measurement of urea concentrations surrounding shrinking briquettes can help assess the effectiveness of the coating in retarding briquette dissolution.
In this paper, radial soil urea concentrations profiles in the vicinity of shrinking kokum wax coated urea briquettes were experimentally determined to check the effectiveness of coating in attenuating soil urea concentration.

\section{Materials and Methods}

Urea concentration was measured in this study by the colorimetric method outlined by Pansu and Gautheyrou [4]. Urea concentration in wet soil, as reported, includes urea present in soil solution plus the quantity adsorbed on solid particles per gram of wet soil. Commercial urea briquettes are ellipsoidal in shape, weigh about $2.1 \mathrm{~g}$ and have average urea content of about $98.5 \%$. Experiments were conducted in silt loam soil. This soil was characterized as per the Indian Standard 2720 [5]. Average properties of the soil are listed in Table 1.

Table 1. Properties of silt loam soil

\begin{tabular}{|c|c|}
\hline Clay content, \% & 5 \\
\hline $\begin{array}{c}\text { Saturation moisture, } \\
\text { g-moisture/g-dry soil }\end{array}$ & 0.40 \\
\hline $\mathrm{pH}$ & 6.02 \\
\hline Organic carbon, $\%$ & 0 \\
\hline
\end{tabular}

Silt loam soil was chosen for the purpose since the soil lacks organic content (Table 1) required for microbial growth, thereby minimizing the effect of urease enzyme which tends to hydrolyze the released urea [6].

Kokum wax is a biodegradable material obtained from seeds of the fruit kokum (Garcinia Indica), a commonly available fruit in the west coast of India. Single layer kokum wax coating (of thickness $230 \pm 21 \mu \mathrm{m}$ ) was applied by immersing briquettes in the molten wax at $45^{\circ} \mathrm{C}$ for two minutes and subsequently filtering the molten wax through a mesh and cooling subsequently to solidify the coating. To measure the thickness of applied coating, the following technique was used [7]. A coated briquette was placed in water and the coating was allowed to rupture. Peeled off 
coating was dried and weighed. The dry coating was subjected to coating thickness measurement using a micrometer. The procedure was repeated to get an average coating thickness and weight.

\section{Soil Urea Concentration Profiles}

In order to investigate the development of concentration profiles around the shrinking kokum wax coated briquettes, urea release experiments were conducted in the silt loam soil maintained at the saturation moisture content of 0.4 g-moisture/g-dry soil (Table 1). One briquette with single layer kokum wax coating was buried centrally in a pot containing wet silt loam soil to a depth of $5 \mathrm{~cm}$ from the surface and urea was allowed to diffuse. The experiment was conducted at a temperature of $27^{\circ} \mathrm{C}$, and up to a time period of 72 hours since the urea release from single layer kokum wax coated briquettes can extend to a maximum period of about 50 hours [3]. In order to obtain soil samples for analysis at different time intervals, the following procedure was adopted [2]. A tube of diameter $5 \mathrm{~mm}$ was inserted into the wet soil and the tube containing wet soil was withdrawn. Then a solid plug is inserted into the tube from top from the opposite end; when the plug was gradually pushed into the tube, a plug of soil sample gets extruded from the other end of tube. The soil plug was sliced at appropriate lengths corresponding to depths in the original column; thus soil samples located at various distances from the briquette were obtained, and the total urea content, mg-urea/g-wet soil, was analyzed. The experiments were repeated till consistent results $( \pm 20 \%)$ were obtained. The results are shown in Figure 1.

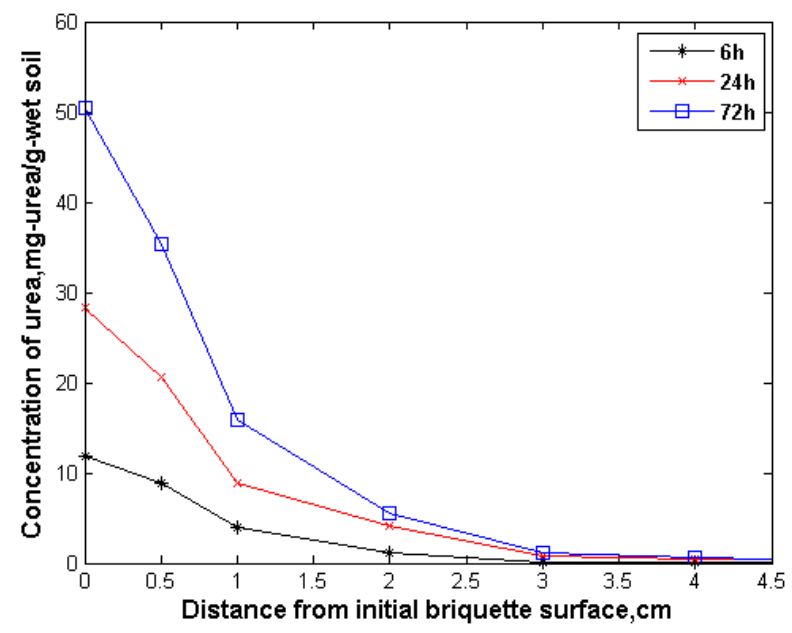

Figure 1. Concentration profile of urea around shrinking kokum wax coated briquettes in silt loam soil

It should be noted that the distances in Figure 1 are the distances from the surface of briquette at start of the experiment. High concentrations of about 195-255 mg-urea/g-wet soil observed at the surface of the uncoated briquettes [2] were not developed in the case of kokum wax coated briquettes. Urea concentration was found to extend to a distance of $3 \mathrm{~cm}$ from the initial surface of the briquette. Hence, it can be concluded that coating urea briquettes alleviates one of the major disadvantage i.e., high concentration of urea around the briquette in soil. With progress of time, urea concentration near the briquette surface increased due to coating rupture.

\section{Conclusions}

High soil urea concentrations were not observed in the case of kokum wax coated briquettes as compared to the corresponding concentrations observed with uncoated briquettes. Although the coatings succumbed to rupture in soils, the maximum soil concentration of urea reached 50 mg-urea/mg-wet soil in about 72 hours, thereby mitigating the ill effects of high soil urea concentration.

\section{REFERENCES}

[1] Savant, N.K. and Stangel, P.J. Deep placement of Urea supergranules in transplanted rice: Principles and practices, Fertilizers Research,25, 1 -83, 1990

[2] Murthy, D.V.R., Ramananada, Bhat M. and Saidutta, M.B. Modeling of urea release from briquettes using semi-infinite and shrinking core models, Chemical Product and Process Modeling, 6(1), article 17, 2011

[3] Murthy, D.V.R., Ramananada, Bhat M. and Saidutta, M.B. Slow release studies on commercial urea briquettes in loam and silty clay soils of Karnataka, India, International Journal of Earth Science and Engineering, 4(2), 351-356, 2011.

[4] Pansu, M. and Gautheyrou, J. Handbook of soil Analysis-Mineralogical, Organic and Inorganic Methods, Springer, Netherlands, p511, 2006.

[5] Indian Standard, IS 2720, Method of Test for Soils. Bureau of Indian Standards (BIS), New Delhi-110002, India, 1985.

[6] Murthy, D.V.R.,Ramananada, Bhat M. and Saidutta, M.B. Urea hydrolysis in saturated loam soil, ARPN Journal of Agricultural and Biological Sciences,6(3), 60-63,2011.

[7] Jarosiewicz, A. and Tomaszewska, M. Controlled Release of NPK fertilizer encapsulated by polymeric membranes, J. Agricultural and Food Chemistry, 51 (2), 413-417, 2003. 